\title{
Recommendations for determining the thickness of the road pavement of technological roads built from coal-bearing rocks
}

\author{
Victor A. Shalamanov ${ }^{1, *}$, Sergey N. Shabaev ${ }^{1}$, and Faruz Alama ${ }^{2}$ \\ ${ }^{1}$ T.F. Gorbachev Kuzbass State Technical University, 28 street Vesennyaya, Kemerovo, 650000, \\ Russian Federation \\ ${ }^{2}$ Lebanese International University, 146404 Mazraa, Mouseitbeh, Lebanon
}

\begin{abstract}
With open-pit mining method in Kuzbass is widely used automobile transport, transportation costs up to $70 \%$ of the cost of coal production. It is not economically feasible to use asphalt concrete and cement concrete as a material of temporary technological roads, and the use of crushed coal-bearing rocks will make it possible to increase the efficiency of coal mining by open method. Currently, the question of the application of the coal-bearing rocks for building temporary technological roads is poorly studied. The paper proposes a method of determining the thickness of road pavements of technological roads, which can be applied directly by the mining company, their analysis has been carried out, the dependence from the strength factor and the category of blockiness of foundation rocks has been determined.
\end{abstract}

\section{Introduction}

Up to $50 \%$ of workers in mining enterprises, with the open-pit mining method are employed in the most expensive and labor-intensive process - transportation of mineral and coal-bearing rocks, transportation costs make up to $70 \%$ of the total costs of mineral extraction. In the implementation of this process is widely used automobile transport, $65 \%$ transportation of rock mass in Russia and up to $90 \%$ abroad.

Asphalt concrete and cement concrete as a material of temporary technological roads cannot be applied, it is not economically appropriate. Application of the fragmented coal-bearing rocks will allow to improve the efficiency of open-pit coal mining and ecological situation in the region. But at present time, the question of using coal-bearing rocks for the building, repair and maintenance of temporary roads has not been sufficiently studied, and therefore the rock is dumped and occupies agricultural land. With that being said determining a road pavements thickness of technological roads built from coal-bearing rocks acquires particular relevance and importance.

\footnotetext{
* Corresponding author: shalamanov49@mail.ru
} 


\section{Materials and methods}

In Kuzbass (Western Siberia, Russia) the open pit mining is the most perspective way to extract coal [1-3]. Taking into consideration the annual cost growth of the road-building materials, it is natural that cost of transportation of the extracted rock mass is also growing. The cost of construction, repair and maintenance of temporary technological roads range from 5 to $15 \%$ of the cost of transportation, they can be reduced by using coal-bearing rocks as road-building materials. We found that more than $50 \%$ coal-bearing rocks of Kuzbass is physically and mechanically comply with requirements for materials which are necessary for building foundations and coatings of technological roads of Kuzbass open-pit mines.

The main factor, affecting service life of technological road - vehicle speed. With it increase deflections are reduced. They are most noticeable at low speeds of motion (up to 20 $\mathrm{km} / \mathrm{h}$ ), which is typical for heavy vehicles, and at more than $40 \mathrm{~km} / \mathrm{h}$ deflections stabilizes . This is explained by the fact that the relationship between the loading time and the corresponding value of the modulus of elasticity is non-linear. For fragmented coal-bearing rocks the modulus of elasticity in the transition from instantaneous loading to long-term exposure varies in 1.11.5 times.

As a calculated value of the modulus of elasticity of the crushed rock, the value obtained by multiplying the static modulus of elasticity (long-term impact of the load) on the coefficient of transition to the instantaneous loading:

$$
E_{r}=E_{s t} \cdot k_{r}
$$

where $E_{r}$ - the calculated modulus of elasticity of the crushed rock, MPa; $E_{s t}-$ static modulus of elasticity of crushed rock, MPa;

$k_{r}$ - the transition coefficient from the effects of continuous load to instantaneous loading.

When designing technological roads, it is assumed that the velocity of movement of vehicles vary from 10 to $25 \mathrm{~km} / \mathrm{h}$, and in the summer period of time for dust removal they are watered with water; in this case, it is advisable to take the calculated elastic modulus value of the crushed rock as the calculated moisture content of the rocks, i.e. .

Features of the technological road pavements calculation, in distinction from the public roads, are as follows:

- loading on the road pavements from rock handlers are significantly higher than loading from motor vehicles moving on public roads;

- calculated values of the strength and deformation characteristics of the coal-bearing rocks differ from the values assumed in the calculation of public road pavements;

- road pavements of technological roads are calculated only by shear stability;

- an indicator of the strength coefficient is introduced when road pavements of technological roads are designed (due to reduced strength coal-bearing rocks during operation).

\section{Results}

One can determine optimum design value of the coefficient of road pavement strength according to the formula proposed by $\mathrm{S}$. Bogomolov:

$$
k_{r}^{p r}=(0.125 \cdot T+0.75) \cdot(0.06 \cdot Q+0.6)
$$

where $T$ - time of operation of the road, years;

$Q$ - the volume of freight on the road, million tons/year.

We propose the following algorithm for calculation the thickness of the road pavement made of coal-bearing rocks:

1. The service life and the load capacity of the technological road are set.

2. The optimum factor of durability of road pavement is calculated by the formula (2). 
3. The type of rock handler used for transportation of the rock mass is selected.

4. Depending on the blockiness category of base rocks, their mechanical properties are accepted.

5. The thickness of the road pavement of the technological road is determined.

Performing numerous calculations of road pavements thickness of technological roads of Kuzbass open-pit mines, constructed of coal-bearing rocks in accordance with the proposed algorithm and analyzed the results, we found that it depends from blockiness category of natural base.

The researchers have not disregarded the issue of using coal-bearing rocks as a material for the construction, repair and maintenance of temporary technological roads in the process of mining in the open way [4-17], but recommendations for determining the thickness of road pavements have not been developed. We have proposed a method of calculation, which can be applied directly to the mining enterprise. To do this, use the above algorithm and the nomogram constructed on the basis of numerous calculations (figure).

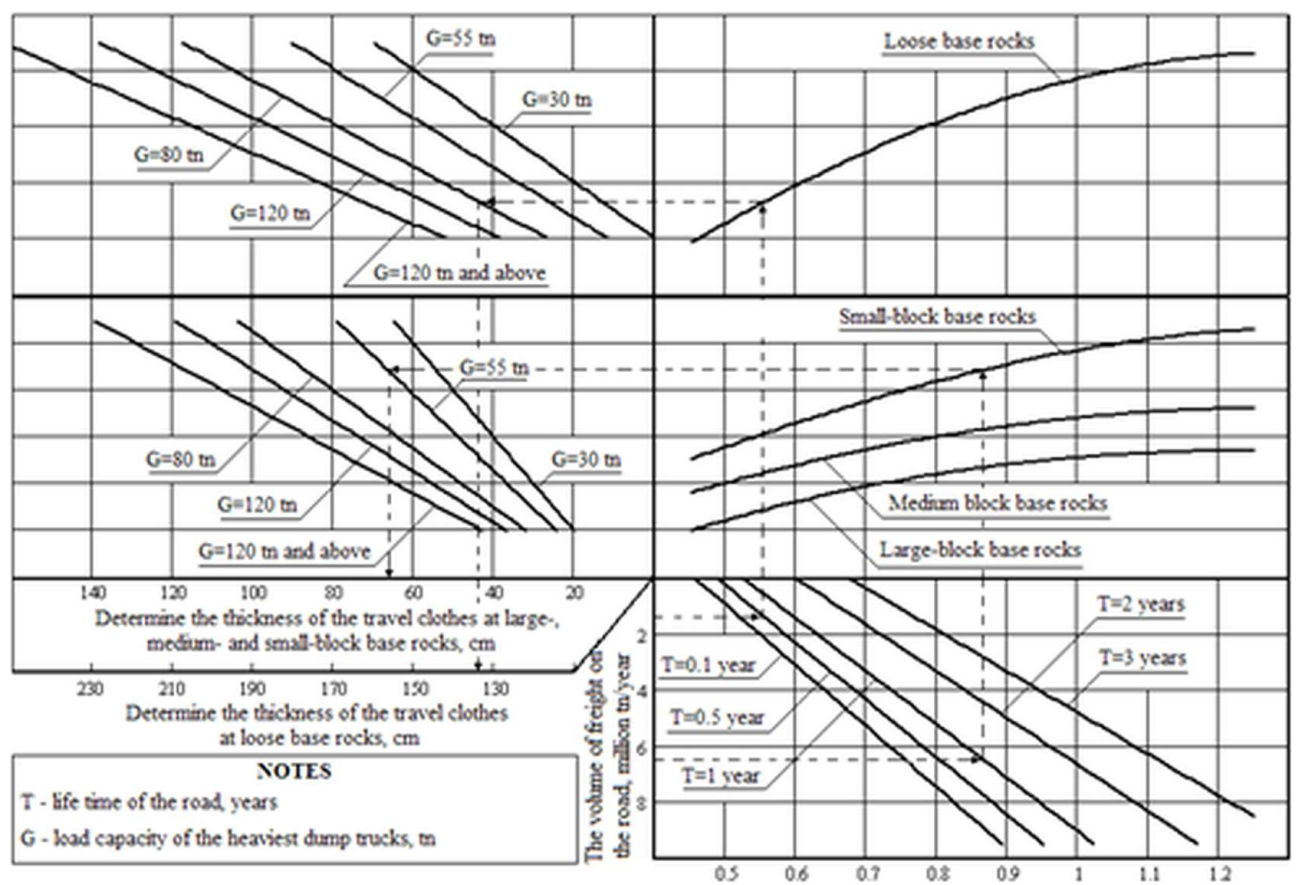

Fig. 1. Nomogram determine the thickness of the travel clothes.

\section{Conclusions}

Our analysis of the thickness of the road pavements of technological roads, which ensure the normal operation of road transport, with the time of operation and road freight volume, showed that they depend mainly on the blocking category of base rocks and the design strength factor and vary from 0.20 in large-block, up to 2.5 meters in loose.

\section{References}

1. T. Gvozdkova, M. Tyulenev, S. Zhironkin, V. A. Trifonov, Yu. M. Osipov, IOP Conf. Ser.: Earth Environ. Sci., 50:1, 012010 (2017) 
2. M. Tyulenev, O. Litvin, S. Zhironkin, M. Gasanov, Acta Montanistica Slovaca, 24:2, 8897 (2019)

3. S. Markov, J. Janočko, M. Tyulenev, Y. Litvin, E3S Web of Conferences, 105, 01021 (2019)

4. V. I. Chernobai, Journal of Coal Science and Engineering, 19:2, 219-225 (2013)

5. D. V. Moldovan, Journal of Industrial Pollution Control, 33:1, 1007-1012 (2017)

6. M.A. Tyulenev, S.O. Markov, M.A. Gasanov, S.A. Zhironkin, Geotech. Geol. Eng., 36:5, 2789-2797 (2018)

7. A.A. Khristoforova, M.D. Sokolova, B. N. Zarovnyaev, A. N. Akishev, Mining Journal, 3, 47-50 (2016)

8. G. V. Solovyev, K. I. Vatchnadze, Procedia Engineering, 189, 666-672 (2017)

9. S. L. Jackson, Geoforum, 66, 94-105 (2015)

10. B. Kinga, M. Goycoolea, A. Newman. European Journal of Operational Research, 257, 297-309 (2017)

11. V. Czermak, H. G. Huckenholz, L. Rybach, Physical properties of rocks (Springer, Berlin, 1982)

12. R. P. Monicard, Properties of reservoir rocks: core analysis (Springer, Berlin, 1980)

13. K. Bucher, Kurt, G. Rodney, Petrogenesis of metamorphic rocks (Springer, Berlin, 2011)

14. I. W. Farmer, Engineering behaviour of rocks (Springer, Berlin, 1983)

15. Lian Ying Zhang, Xian Biao Mao, Ai Hong Lu, Science in China Series E: Technological Sciences, 52:3, 641-646 (2009)

16. A. Kilic, A. Teymen, Bulletin of Engineering Geology and the Environment, 67, 237 (2008)

17. Zong-Xian Zhang, Journal of Rock Mechanics and Geotechnical Engineering, 8:6, 886895 (2016) 